\title{
Estimating the impact of the 2009 influenza A(H1N1) pandemic on mortality in the elderly in Navarre, Spain
}

J Castilla (jcastilc@navarra.es) ${ }^{1}$, J Etxeberria ${ }^{1}$, E Ardanaz $^{1}$, Y Floristán ${ }^{1}$, R López Escudero $^{1}$, M Guevara $^{1}$

1. Public Health Institute of Navarre and Centro de Investigación Biomédica en Red de Epidemiología y Salud Pública (CIBERESP, Biomedical Research Network of Epidemiology and Public Health), Pamplona, Spain

Citation style for this article:

Citation style for this article: Castilla J, Etxeberria J, Ardanaz E, Floristán Y, López Escudero R, Guevara M. Estimating the impact of the 2009 influenza A(H1N1) pandemic on mortality in the elderly in Navarre, Spain. Euro Surveill. 2010;15(5):pii=19481. Available online: http://www.eurosurveillance.org/ViewArticle. aspx?Articleld $=19481$

This article has been published on 4 February 2010

We analysed mortality among people aged 65 years or older in Navarre, Spain in 2009 and compared it with the mean for the same period of time in the previous three years. In the pandemic weeks 24 to 52 2009 we observed $4.9 \%$ more deaths than expected $(p=0.0268)$. Excess mortality occurred during the circulation of seasonal influenza $(8.0 \%, p=0.0367)$ and the first wave of pandemic influenza (9.9\%, $p=0.0079)$. In the second wave of pandemic influenza there was a non-significant excess of deaths $(5.2 \%, p=0.1166)$. Surveillance of laboratory-confirmed severe influenza cases detected only one death in this age group.

\section{Introduction}

Influenza has usually been associated with increased mortality in the elderly [1-4]. However, the large majority of influenza cases are not laboratory-confirmed, and only a small part of the excess deaths occurring in periods when influenza virus is circulating are registered as deaths caused by influenza [5].

The 2009 influenza $A\left(\mathrm{H}_{1} \mathrm{~N}_{1}\right)$ pandemic coincided with increased use of laboratory techniques to confirm influenza cases, although confirmation was limited to only a small proportion of all possible cases [6]. In Spain, as in other developed countries, influenza testing has been systematically incorporated for all patients hospitalised with acute respiratory disease [7]. From the standpoint of epidemiological surveillance, this was interpreted to mean that the large majority of severe cases and of deaths from the influenza virus can now be confirmed [8]. Based on this information, the 2009 pandemic influenza $A\left(\mathrm{H}_{1} \mathrm{~N}_{1}\right)$ virus has been related to a relatively low number of deaths in patients with laboratory-confirmed results, a small proportion of which occurred in elderly people [9-11].

The objective of this study was to evaluate the possible repercussions of the circulation of the 2009 pandemic influenza on mortality in adults aged 65 years and older.

\section{Methods}

The study was carried out in Navarre, Spain (a region of 620,000 inhabitants). Influenza surveillance in this region is based on automatic reporting of cases of influenza-like illness diagnosed in primary healthcare and hospitals. Virological surveillance includes weekly reports from all three laboratories that perform influenza tests to confirm the causative agent. Through a sentinel network composed of a representative sample of 76 general practitioners and primary healthcare paediatricians covering $18 \%$ of the population, nasopharyngeal swabs were taken from systematically selected patients with influenza-like illness, after receiving informed consent from the patients or their parents. Hospitalised patients with acute respiratory disease were swabbed for influenza virus testing in accordance with hospital protocols until week 20 of 2009. Swabbing was subsequently extended to all patients who were treated in emergency rooms or hospitalised with acute severe respiratory disease possibly caused by influenza. Swabs were processed in the laboratory by reverse transcription polymerase chain reaction (RT-PCR) and virus culture. Positive samples were characterised for influenza A (subtypes $\mathrm{H}_{1}$ and $\mathrm{H}_{3}$ ) and influenza $B$ virus using immunofluorescence and RT-PCR. Starting in June, real-time RT-PCR for detection of the 2009 influenza $\mathrm{H}_{1} \mathrm{~N}_{1}$ virus was performed on all swabs.

Based on the incidence of reported influenza-like illness and the type of influenza virus in circulation in the region, we distinguished six periods in 2009. Between weeks 1 and 8, a wave of seasonal influenza was identified, with $94 \%$ of the circulating strains corresponding to type $A\left(\mathrm{H}_{3} \mathrm{~N}_{2}\right)$. From week 9 to 15 , there was only sporadic circulation of influenza $B$, with very low incidence. Between weeks 16 and 23, no influenza virus was detected (inter-seasonal period). From week 24 to 35 , influenza activity re-emerged with all 98 positive swabs corresponding to the 2009 pandemic influenza $\mathrm{A}\left(\mathrm{H}_{1} \mathrm{~N}_{1}\right)$ virus (first wave of pandemic influenza). From week 36 to 39 , sporadic detection of this strain continued, with low incidence of influenza-like illness (pandemic remission period). From week 40 to 49 there was a large wave of influenza with high incidence and all circulating strains corresponding to the 2009 pandemic influenza virus (second wave of pandemic influenza). Finally, from week 50 to 52 there was a new remission 
period with low incidence and only sporadic detection of 2009 pandemic influenza $A\left(\mathrm{H}_{1} \mathrm{~N}_{1}\right)$.

In the present study we used information from computerised mortality registers, which cover approximately $70 \%$ of the population $(76,201$ adults aged 65 years or older) and of the deaths in the region and provide information in real time. We analysed all deaths reported in adults aged 65 years or older in 2009 and compared them with the expected number of deaths, calculated as the average of deaths for the same periods of the three preceding years (2006, 2007 and 2008). For comparison we used the periods defined according to the incidence and the type of influenza virus in circulation in Navarre in 2009. Poisson distribution was used to compare observed and expected deaths.

Rates were calculated with the population covered by the computerised registers on 1 January of each year taken as the denominator. Standardised mortality ratios were obtained using the population on 1 January 2009 as the reference population. Available age groups were $65-69,70-74,75-79,80-84$ and $\geq 85$ years.

\section{Results}

Active epidemiological and virological surveillance of influenza detected the first laboratory-confirmed case of 2009 pandemic influenza $A\left(\mathrm{H}_{1} \mathrm{~N}_{1}\right)$ in Navarre in week 24 of 2009 . Between that date and the end of
2009, 3,190 swabs were tested for influenza, and 933 cases of laboratory-confirmed 2009 pandemic influenza $A\left(\mathrm{H}_{1} \mathrm{~N}_{1}\right)$ were detected. The number of cases of influenza-like illness that received medical attention reached 37 cases per 1,000 population $(n=22,374)$. During 2009, 223 patients diagnosed with 2009 pandemic influenza in Navarre required hospitalisation, 17 of them required admission to intensive care units, and four died. In adults aged 65 years and older, 829 tests for influenza were performed, 28 patients with confirmed 2009 pandemic influenza required hospital admission, two in intensive care units, and one person died.

The Figure shows the number of deaths per week observed in persons aged 65 years or older compared with the number of expected deaths, and indicates the periods with influenza activity in 2009 and in the reference years. In the pandemic period (weeks 24 to 52) 1,671 deaths were registered in persons aged 65 years or older, $4.9 \%$ more than expected $(p=0.0268)$. In contrast, in the weeks without circulation of pandemic virus (weeks 1 to 23), there was no significant difference between observed and expected deaths (Table 1).

Table 2 shows the mortality in short periods based on incidence of influenza-like illness and the type of virus circulating in the region. Statistically significant excess mortality among adults aged 65 years or older

\section{FIGURE}

Number of deaths per week registered and expected (mean of the three previous years) in the population aged 65 years or older covered by computerised death registers, Navarre, 2009

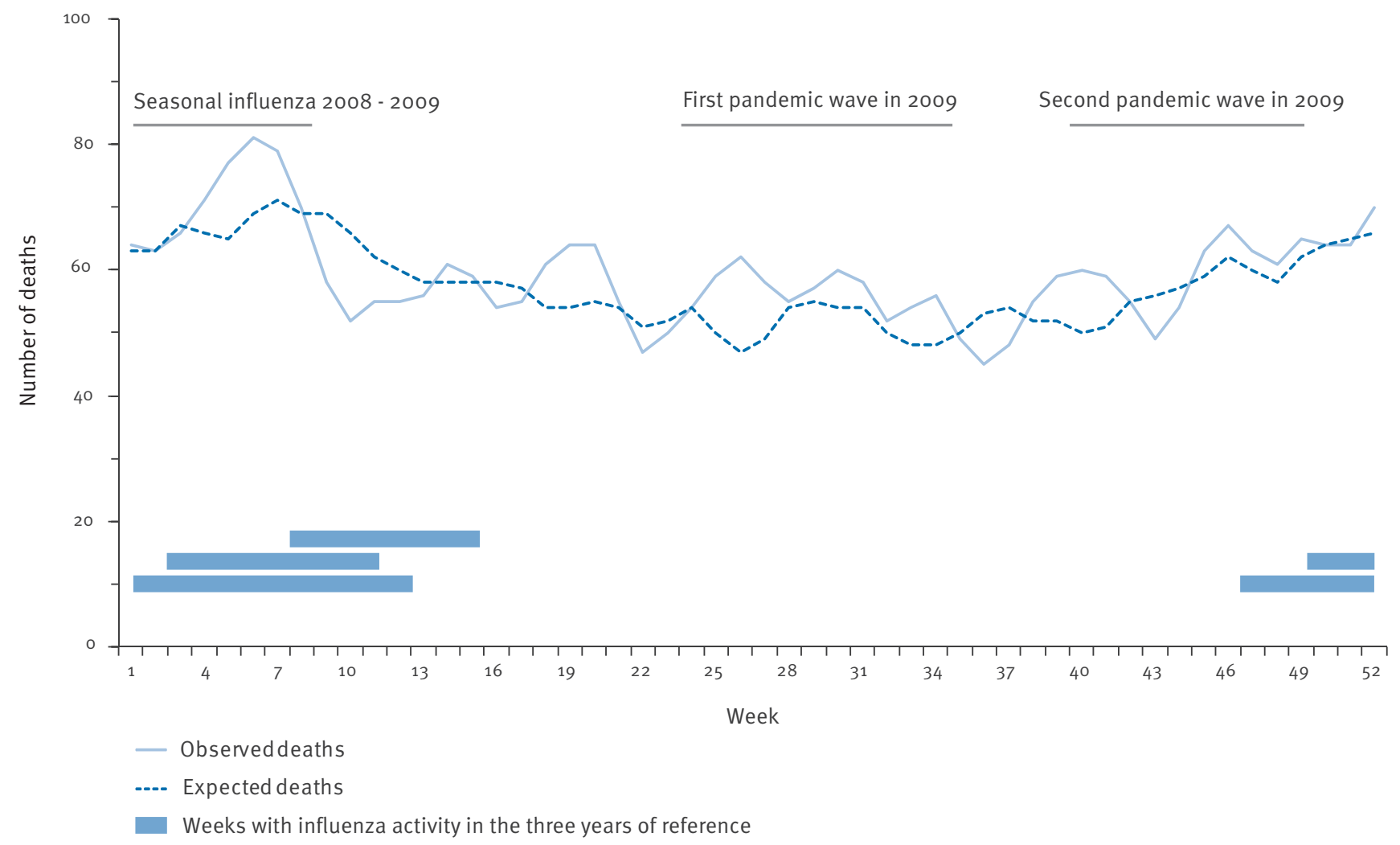

The data represented are moving averages calculated over three values with weights $0.25,0.5,0.25$. 
TABLE 1

Mortality among adults aged 65 years or older in the population covered by computerised death registers in Navarre, 2006-2009

\begin{tabular}{|l|c|c|}
\hline & $\begin{array}{c}\text { Non-pandemic period } \\
\text { weeks 1 to 23 }\end{array}$ & $\begin{array}{c}\text { Pandemic period } \\
\text { weeks 24 to 52 }\end{array}$ \\
\hline $\begin{array}{l}\text { Expected deaths (annual } \\
\text { average for 2006-2008) }\end{array}$ & 1,390 & 1,593 \\
\hline $\begin{array}{l}\text { Observed deaths in } \\
\text { 2009 }\end{array}$ & 1,410 & 1,671 \\
\hline Percentage of change & $+1.4 \%$ & $+4.9 \%$ \\
\hline P value & 0.2993 & 0.0268 \\
\hline \multicolumn{2}{|l|}{} \\
\hline $\begin{array}{l}\text { Annual average mortal- } \\
\text { ity rate for 2006-2008 }\end{array}$ & 4,255 & 3,867 \\
\hline Mortality rate in 2009 & & 3,946 \\
\hline Percentage of change & 4,198 & $+2.0 \%$ \\
\hline P value & $-1.3 \%$ & 0.4753 \\
\hline \multicolumn{2}{|l|}{} \\
\hline $\begin{array}{l}\text { Standardised mortality } \\
\text { ratio }\end{array}$ & 0.6785 & 1.00 \\
\hline
\end{tabular}

was observed in periods with circulation of seasonal or pandemic influenza virus, but not in periods when influenza activity was low or absent. There was an excess mortality of $8.0 \%(p=0.0367)$ in the seasonal influenza period compared with the expected number of deaths. There was also an excess mortality of $9.9 \%$ $(p=0.0079)$ coinciding with the first wave of pandemic influenza, and again an excess mortality of $5.2 \%$ in the second wave, although the latter did not reach statistical significance $(p=0.1166)$ (Table 2$)$.

During the study there were no other known causes that could explain the excess mortality observed. In the summer of 2009, the heat alert threshold (minimum temperature of $21.5^{\circ} \mathrm{C}$ ) was not exceeded at any time in Navarre, and the days with highest mortality did not coincide with the hottest days.

When we repeated the comparisons, taking as the reference the mean number of deaths in the same period in the previous five years, the main study findings were not affected.

a Rates per 100,000 person-years.

TABLE 2

Epidemiological and virological surveillance of influenza in all ages, and mortality in the population aged 65 years or older, in six periods with circulation of different influenza viruses, Navarre, 2009

\begin{tabular}{|c|c|c|c|c|c|c|c|}
\hline & $\begin{array}{c}\text { Weeks } 1 \\
\text { to } 8\end{array}$ & $\begin{array}{c}\text { Weeks } 9 \\
\text { to } 15\end{array}$ & $\begin{array}{c}\text { Weeks } \\
16 \text { to } 23\end{array}$ & $\begin{array}{l}\text { Weeks } \\
24 \text { to } 35\end{array}$ & $\begin{array}{c}\text { Weeks } \\
36 \text { to } 39\end{array}$ & $\begin{array}{c}\text { Weeks } \\
40 \text { to } 49\end{array}$ & $\begin{array}{c}\text { Weeks } \\
50 \text { to } 52\end{array}$ \\
\hline \multicolumn{8}{|l|}{ Medically-attended influenza-like illness } \\
\hline Number of cases & 6,683 & 680 & 182 & 2,495 & 1,385 & 17,578 & 1,175 \\
\hline Incidence rate per 1,000 inhabitants & 10.9 & 1.1 & 0.3 & 4.1 & 2.3 & 28.2 & 1.9 \\
\hline \multicolumn{8}{|l|}{ Laboratory-confirmed influenza in sentinel network } \\
\hline Swabs from sentinel network patients & 107 & 19 & 27 & 245 & 64 & 419 & 62 \\
\hline Number of laboratory-confirmed cases (\%) & $57(53 \%)$ & $\begin{array}{c}12 \\
(63 \%) \\
\end{array}$ & o (o\%) & $\begin{array}{c}98 \\
(39 \%) \\
\end{array}$ & $2(3 \%)$ & $\begin{array}{c}213 \\
(51 \%)\end{array}$ & $\begin{array}{c}14 \\
(23 \%)\end{array}$ \\
\hline Circulating influenza strains & $\begin{array}{c}\mathrm{A}\left(\mathrm{H}_{3} \mathrm{~N}_{2}\right) \\
\mathrm{a}\end{array}$ & B & None & $\begin{array}{c}2009 \\
\mathrm{~A}\left(\mathrm{H}_{1} \mathrm{~N}_{1}\right)\end{array}$ & $\begin{array}{c}2009 \\
A\left(\mathrm{H}_{1} \mathrm{~N}_{1}\right)\end{array}$ & $\begin{array}{c}2009 \\
A\left(\mathrm{H}_{1} \mathrm{~N}_{1}\right)\end{array}$ & $\begin{array}{c}2009 \\
A\left(\mathrm{H}_{1} \mathrm{~N}_{1}\right) \\
\end{array}$ \\
\hline \multicolumn{8}{|l|}{ Laboratory-confirmed influenza among hospitalised patients } \\
\hline Hospitalised patients & 12 & 3 & o & 52 & 14 & 143 & 14 \\
\hline Intensive care units & 2 & o & o & 6 & 3 & 7 & 1 \\
\hline Deaths & 0 & o & 0 & o & 0 & 4 & o \\
\hline \multicolumn{8}{|l|}{ Deaths in population aged 65 years or older } \\
\hline Expected number (annual average for 2006-2008 period) & 528 & 432 & 431 & 612 & 216 & 569 & 197 \\
\hline Observed number in 2009 & 570 & 395 & 445 & 673 & 207 & 598 & 193 \\
\hline Percentage of change & $+8.0 \%$ & $-8.6 \%$ & $+3.3 \%$ & $+9.9 \%$ & $-4.0 \%$ & $+5.2 \%$ & $-1.9 \%$ \\
\hline Pvalue & 0.0367 & 0.0346 & 0.2563 & 0.0079 & 0.2748 & 0.1166 & 0.6217 \\
\hline \multicolumn{8}{|l|}{ Mortality rates in population aged 65 or older } \\
\hline Annual average mortality rate for $2006-2008$ period $^{\star \star}$ & 5,305 & 4,344 & 3,789 & 3,591 & 3,795 & 4,002 & 4,614 \\
\hline Mortality rate in $2009^{b}$ & 5,576 & 3,864 & 3,809 & 3,840 & 3,544 & 4,095 & 4,405 \\
\hline Percentage of change & $+5.1 \%$ & $-11.0 \%$ & $+0.5 \%$ & $+6.9 \%$ & $-6.6 \%$ & $+2.3 \%$ & $-4.5 \%$ \\
\hline Standardised mortality ratio & 1.03 & 0.87 & 0.98 & 1.05 & 0.91 & 1.00 & 0.93 \\
\hline
\end{tabular}

a Influenza $A\left(\mathrm{H}_{3} \mathrm{~N}_{2}\right)$ : $94 \%$; seasonal influenza $A\left(\mathrm{H}_{1} \mathrm{~N}_{1}\right)$ : $2 \%$; influenza $B$ : $4 \%$.

${ }^{b}$ Rate per 100,000 person-years. 


\section{Discussion}

Our results suggest excess mortality affecting older adults that coincided with the time when the 2009 pandemic influenza was in circulation. Similar excess mortality has also been observed to coincide with circulation of the seasonal influenza virus, but not in periods with little or no influenza activity. Most of the excess deaths in our study were not identified as influenza deaths, despite systematic testing during the pandemic period of cases with acute respiratory disease requiring hospital admission, as well as a substantial number of patients in primary and emergency care. By focusing concern on deaths occurring in persons with laboratory-confirmed 2009 pandemic influenza $A\left(\mathrm{H}_{1} \mathrm{~N}_{1}\right)$ [8-11] this additional mortality may not be detected. It is possible that some of these deaths occurred outside the hospital, or that the influenza was hidden by another underlying pathology. Previous studies have suggested that influenza can trigger or exacerbate non-infectious pathologies such as cardiovascular diseases [12].

Our study was ecological in design; therefore causes other than the influenza pandemic could explain the detected excess mortality. However, the fact that the excess mortality coincided with periods of viral circulation, whether seasonal or pandemic, lends some strength to this hypothesis. Moreover, we reviewed and ruled out other causes that are most frequently associated with excess mortality in the older population. Carrying out the study in a relatively small geographic area allowed us to discriminate between periods of clear influenza activity and those in which influenza was absent. This made it possible to establish more precisely the temporal coincidence between influenza circulation and excess deaths, an association that may be diluted when larger geographic areas are analysed.

Some possible biases have to be considered. The population aged 65 years or older increased by $3 \%$ from the period between 2006 and 2008 to 2009, and the population aged 85 years and over increased by $10 \%$. This explains the differences between the results in absolute numbers and rates, with predominance of general upward trends in the absolute number of deaths and downward trends in crude and adjusted mortality rates. These changes in the population produce a greater number of deaths, regardless of other factors, but do not affect adjusted mortality rates. On the contrary, if the influenza has produced an increase in mortality, it may be partially hidden by the descending secular trend in the general mortality. Therefore, similar comparisons of observed versus expected mortality in periods with and without influenza activity allow us to estimate the impact of the influenza on mortality, avoiding the mentioned biases.

The source of mortality data represents a large and stable proportion of the population of Navarre. The registers include deaths occurring in the major municipalities, but do not include deaths in the Navarre population that have occurred outside these municipalities. This probably has little consequence when analysing the population aged 65 years or older, given their low geographic mobility. In any case, it seems appropriate to evaluate the association between influenza circulation (acute disease) and deaths occurring in the same place, regardless of whether or not it is the usual residence.

The method of analysis used probably does not allow us to show the impact of influenza on mortality in all its magnitude. Other factors affecting mortality could have been present in the reference periods of the previous three years, which would tend to attenuate the excess mortality shown in 2009. For example, waves of seasonal influenza also occurred in the reference years, which affected the periods between the first fifteen and last six weeks in the year (Figure). This could explain why the deaths coinciding with the summer wave of pandemic influenza were clearly shown as excess mortality, whereas excess mortality during the times of the year when influenza is usually present may have been partially hidden by including in the reference periods weeks in which seasonal virus was circulating in previous years.

In conclusion, these results suggest that the 2009 pandemic influenza $A\left(\mathrm{H}_{1} \mathrm{~N}_{1}\right)$ may have been accompanied by increased mortality in older persons, which would not have been detected by looking for cases of acute respiratory disease in hospitals, either because the death could have occurred outside the hospital or because influenza infection was not suspected.

\section{Acknowledgements}

This work was supported in part by the Fondo de Investigación Sanitaria, Instituto de Salud Carlos III (PIo61346).

\section{References}

1. Glezen WP. Serious morbidity and mortality associated with influenza epidemics. Epidemiol Rev. 1982;4:25-44.

2. Thompson WW, Shay DK, Weintraub E, Brammer L, Cox $\mathrm{N}$, Anderson LJ, et al. Mortality associated with influenza and respiratory syncytial virus in the United States. JAMA. 2003;289(2):179-86.

3. Thompson WW, Shay DK, Weintraub E, Brammer L, Bridges CB, Cox NJ, et al. Influenza-associated hospitalizations in the United States. JAMA. 2004;292(11):1333-40.

4. Nicholson KG, Wood JM, Zambon M. Influenza. Lancet. 2003;362(9397):1733-45.

5. Reichert TA, Simonsen L, Sharma A, Pardo SA, Fedson DS, Miller MA. Influenza and the winter increase in mortality in the United States, 1959-1999. Am J Epidemiol. 2004;160(5):492-502.

6. Novel Swine-Origin Influenza $A\left(\mathrm{H}_{1} \mathrm{~N}_{1}\right)$ Virus Investigation Team. Emergence of a novel swine-origin influenza $A\left(\mathrm{H}_{1} \mathrm{~N}_{1}\right)$ virus in humans. N Engl J Med. 2009;360(25):2605-15.

7. Plan Nacional de Preparación y Respuesta ante una pandemia de gripe. Vigilancia epidemiológica de casos humanos de infección por virus pandémico $\left(\mathrm{H}_{1} \mathrm{~N}_{1}\right)$ 2009. [National preparedness and response plan before an influenza pandemic. Epidemiology surveillance of human cases of infection with the pandemic virus $\left(\mathrm{H}_{1} \mathrm{~N}_{1}\right)$ 2009]. Madrid: Ministerio de Sanidad y Políticas Sociales; 2009. http:// www.msps.es/profesionales/saludPublica/gripeA/docs/ VigilanciaVirusPandemic02009.pdf. Spanish. 
8. Donaldson LJ, Rutter PD, Ellis BM, Greaves FEC, Mytton OT, Pebody RG, et al. Mortality from pandemic A/H1N1 2009 influenza in England: public health surveillance study. BMJ. 2009;339:b5213. Doi:10.1136/bmj.b5213.

9. The ANZIC influenza Investigators. Critical care services and $2009 \mathrm{H}_{1} \mathrm{~N}_{1}$ influenza in Australia and New Zealand. N Engl J Med. 2009;361(20):1925-34.

10. Echeverría-Zuno S, Mejía-Aranguré JM, Mar-Obeso AJ, GrajalesMuñiz C, Robles-Pérez E, González-León P, et al. Infection and death from influenza A H1N1 virus in Mexico: a retrospective analysis. Lancet. 2009;374(9707):2072-79.

11. Kelly H, Grant K. Interim analysis of pandemic influenza $\left(\mathrm{H}_{1} \mathrm{~N}_{1}\right) 2009$ in Australia: surveillance trends, age of infection and effectiveness of seasonal vaccination. Euro Surveill. 2009;14(31):pii=19288. Available from: http://www. eurosurveillance.org/ViewArticle.aspx?Articleld=19288

12. Nichol KL, Nordin J, Mullooly J, Lask R, Fillbrandt K, Iwane M. Influenza vaccination and reduction in hospitalizations for cardiac disease and stroke among the elderly. N Engl J Med. 2003;348(14):1322-32. 